\title{
An investigation of material removal rate and kerf on WEDM through grey relational analysis
}

\author{
J.M.Pujara $^{1 *}$, K.D.Kothari ${ }^{2}$ and A.V.Gohil ${ }^{3}$ \\ ${ }^{1}$ Research Scholar, RK University, Rajkot and Assistant Professor \\ Government Engineering College, Rajkot - 360005 \\ *Email: jay.rkcet@gmail.com \\ Phone: +91 9825774197 \\ ${ }^{2}$ Associate Professor and Head, Mechanical Engineering Department, \\ RK University, Rajkot - 360020 \\ ${ }^{3}$ Professor and Head, Production Engineering Department, \\ Shantilal Shah Engineering College, 364060, Bhavnagar
}

\begin{abstract}
This paper describes an investigation on the optimization of process parameters on the Material Removal Rate (MRR) and kerf in Wire Electrical Discharge Machining (WEDM) operations. The experiments were carried out under varying pulse ON/OFF time, peak current, and wire feed by using Taguchi L9 orthogonal array. Grey Relational Analysis (GRA) optimization technique is used to find the optimal selection of process parameters for improvement in WEDM performance. The deviation of the kerf and material removal rate with process parameters is mathematically modeled by using Response Surface Methodology (RSM). The adequacy of the developed mathematical models is checked by Analysis of Variance (ANOVA). The problem is formulated as a multi-objective optimization as the influence of process input variables on material removal rate and kerf is conflicting in nature. Based on statistical analysis, it has been found that pulse on time, peak current is adequately influential parameters for MRR while pulse off time, peak current, and wire feed adequately influential for the kerf. Confirmation test result shows the application of the optimization technique for predicting optimal combinations of input variables for better output responses.
\end{abstract}

Keywords: Wire electrical discharge machining; metal matrix composites; material removal rate; kerf; response surface methodology; optimization.

\section{INTRODUCTION}

Electric Discharge Machining utilizes the discharge of electric current and thus material has been removed with the help of conducting wire known as Wire Electric Discharge Machining (WEDM). It has been applicable for two-dimensional as well as threedimensional intricate and complex shapes for the machining with the workpiece being electrically conductive. The material eroded due to spark thus produced will be flushed out with the help of flushing dielectric fluid forced to pass through the gap between electrode and workpiece. Due to the higher accuracy in dimensions obtained from this process, it accounts for the industry requiring higher surface finish value with minimum deviation from dimensions like in surgical instruments, stamping dies, prototype parts etc. Precision dies when made involves many machining operations for the higher precision value that can be eliminated by using WEDM process. 
Significant effects found on machining are given by the responses like Material Removal Rate (MRR) or machining rate, surface finish or roughness of the surface obtained after machining and kerf or a width obtained during cutting [1]. Out of these responses kerf (Figure 1), plays a vital role as it accounts for the dimensional accuracy obtained in the finished workpiece. It also limits the internal corner radius to be produced in the machined part. The gap between wire and work is generally in the range of $0.025 \mathrm{~mm}$ to $0.075 \mathrm{~mm}$ as per the requirement and is constantly maintained by the computer controlled system for the positioning of the wire. Calculations for the kerf includes the addition of wire diameter (in the range of $0.05 \mathrm{~mm}$ to $0.4 \mathrm{~mm}$ ) and twice the wire work gap as it is on both sides of the wire can be represented mathematically $\left(D_{w}+2 \times L_{g}\right)$. Another important parameter is MRR as its value is directly affecting the economics of machining and production rate. Economics of machining means profitability in machining which can be achieved by higher machining rate as more number of the workpiece can be machined in a given time interval and thus more material to be removed which is material removal rate. Thus the main goal in machining is to attain a maximum value of MRR with the minimum value of kerf but both cannot be simultaneously achieved and thus parameters needed to be optimized to get both the values improved without affecting the minimum requirement of each parameter. The value of machining parameters strongly relies on the experience of the operator and also with available parameter table provided by tool supplier. Optimization of process parameters approached using artificial neural network (ANN) method for the responses waviness of workpiece, surface roughness and cutting speed [2]. The authors have experimented to study the effects of machining parameters and its variation on MRR, surface roughness and gap width. They have succeeded in determining the significance of parameters for MRR but they did not determine the other two responses instead represented them in a simple graphical way [3]. The researchers have worked with two different workpiece which was advanced ceramics to study the comparison of machining performance for MRR and surface finish compared with the different machining conditions [4]. Another study has selected responses as the depth of white layer on the machined workpiece, gap width, and surface roughness and studied effects experimentally [5]. Metal Matrix Composite (MMC) have been used as the work material to investigate the variation of machine feed rate and surface roughness with a variation of machining parameters [6].

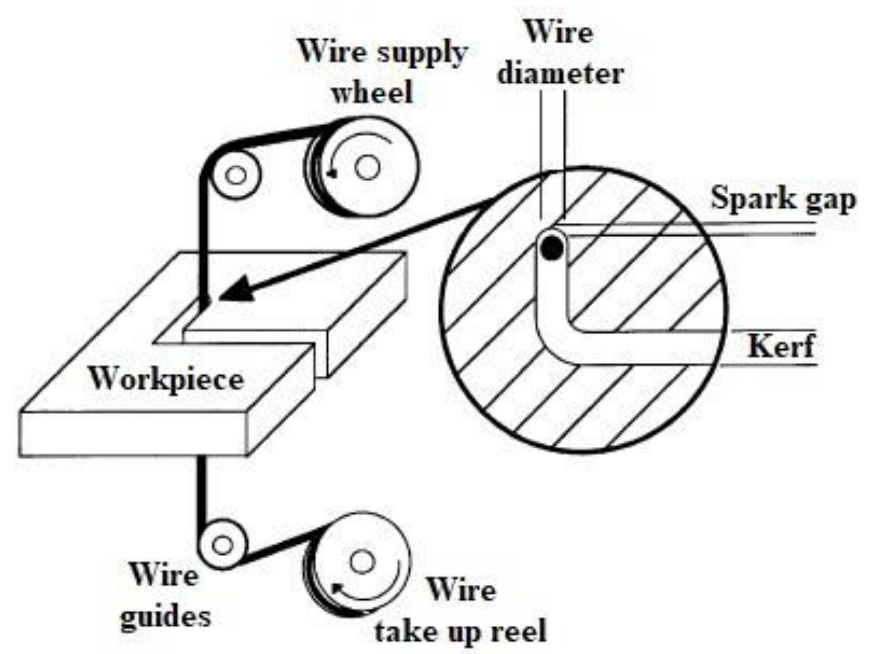

Figure 1. Detail of WEDM cutting [1]. 
The literature available for the method suggests that most researchers have worked with responses like MRR, surface roughness, cutting speed, wire rupture but very little known work have been found or no work on kerf and its variance statically with parameters in WEDM. That has been the research gap and thus a combination of MRR along with kerf has been discussed in this article. The variation of kerf and MRR with the parameters have been studied and then set of parameters investigated experimentally and from that data, a statistical model generated. From the statistical model optimum set of parameters found for the improved value of MRR and kerf. This article shows statistical evaluation using analysis of variance (ANOVA) for the effect of parameters and their level of significance. The multi-response output is introduced with the low kerf and high MRR goal to analyze multi-objective function. Machining parameters selected for study are pulse On/Off time, peak current and wire feed and setting of their values have been determined by using grey relational analysis.

\section{EXPERIMENTAL WORK}

\section{Material, Machining study, and Measurement}

The experimental studies were performed on EZEECUT plus CNC wire cut machine tool at Surelia wire cut Pvt. Ltd industries at Rajkot. Different settings of pulse ON/OFF time, peak current, and wire feed used in the experiments are presented in Table 1. Molybdenum wire of $0.18 \mathrm{~mm}$ diameter having a tensile strength of $900 \mathrm{~N} / \mathrm{mm}^{2}$ was used in the experiments. LM6 aluminum alloy reinforced with SiCp (Silicon carbide particulate) $5 \%$ by weight means $5 \mathrm{~g}$ particulates per $100 \mathrm{~g}$ weight of the base material composites in the form of a rectangular plate (size $95 \times 20 \times 10 \mathrm{~mm}$ ) is used as workpiece material. Aluminium-silicon matrix (LM6) alloy has a potential application in the field of automotive industries that is at parts like rotors of brakes, in the brake drum and in discs used for the break as it provides the parts with lower weight to strength ratio, high wear resistance, and high thermal conductivity. Taguchi's L9 design matrix for experiments with different level combination has been selected.The value of the levels was selected on the basis of literature available as well as pilot experiments. The experimental set up is shown in Figure 2. Line diagram of the sample is shown in Figure 3. The distance between two successive cuts was maintained as $8 \mathrm{~mm}$. Figure 4 and Figure 5 shows the work material during machining and after conducting the experiments. Coolant oil was used as the dielectric for experiments, as that is the standard for Wire EDM. The performance measure was selected on the basis of its applications which are kerf and material removal rate as they are main measures. The kerf is the actual size (cutting width) of the cut made in the workpiece along the path length for an input condition. It is measured by using an inverted optical microscope with a maximized view and represented in millimeters. MRR is calculated by using the following equation [7].

$$
M R R=k t c s m^{3} / \mathrm{min}
$$

Where $k$ is the kerf $(\mathrm{mm}), t$ is the thickness of workpiece $(10 \mathrm{~mm})$, and $c s$ is cutting speed $(\mathrm{mm} / \mathrm{min})$. So the data of kerf and MRR after the experiments have been listed in Table 2. 


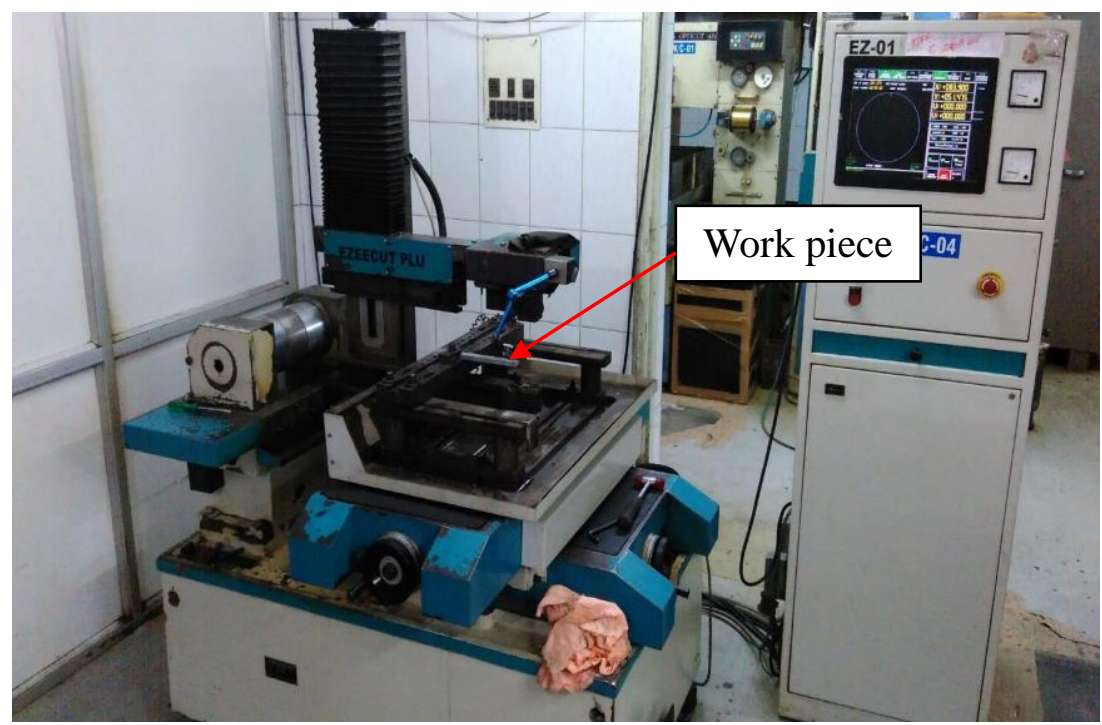

Figure 2. EZEECUT Plus CNC WEDM Machine tool.

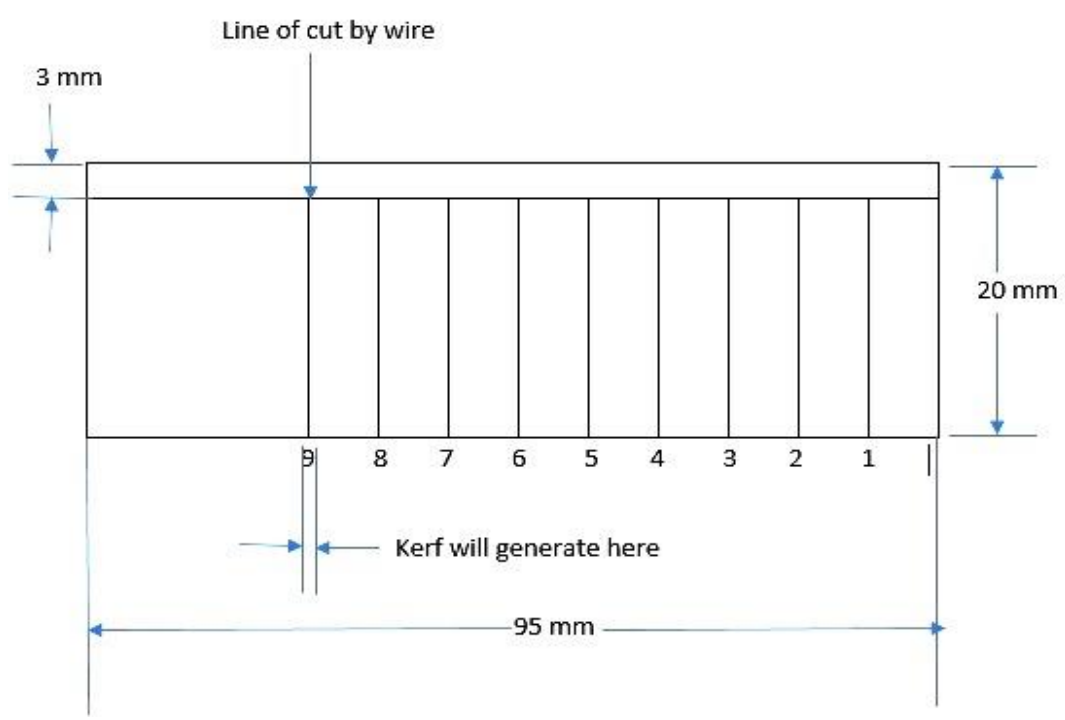

Figure 3. Line diagram of the sample.

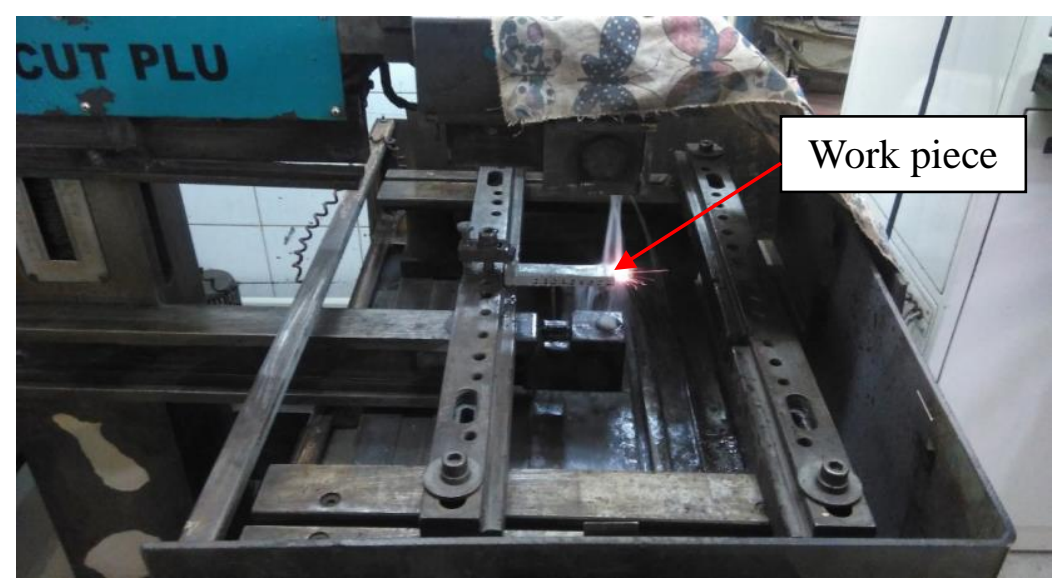

Figure 4. Work material during machining. 


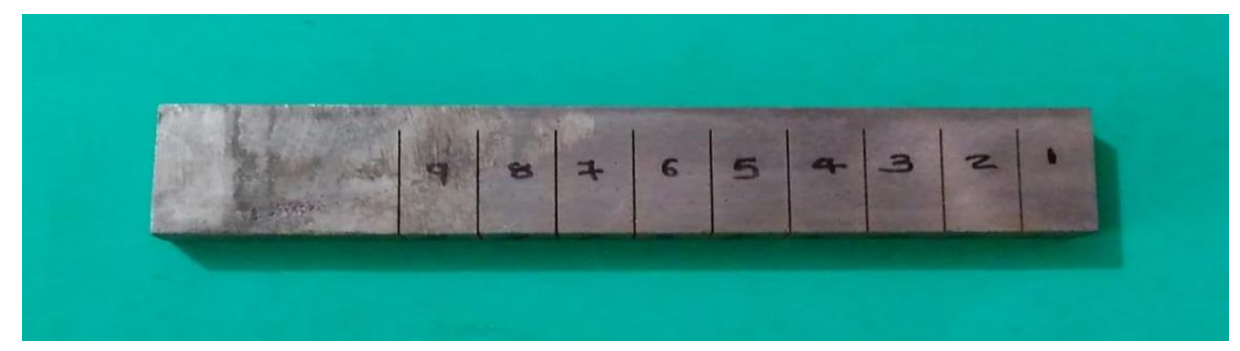

Figure 5. Work material after conducting experiments.

Table 1. Control variables and their levels.

\begin{tabular}{lcccc}
\hline \multirow{2}{*}{ Parameters } & \multirow{2}{*}{ Notations } & \multicolumn{3}{c}{ Levels } \\
\cline { 3 - 5 } & & -1 & 0 & 1 \\
\hline $\mathrm{T}_{\text {on }}(\mu \mathrm{s})$ & $\mathrm{X}_{1}$ & 8 & 10 & 12 \\
$\mathrm{~T}_{\text {off }}(\mu \mathrm{s})$ & $\mathrm{X}_{2}$ & 7 & 10 & 13 \\
$\mathrm{IP}(\mathrm{A})$ & $\mathrm{X}_{3}$ & 1 & 2 & 3 \\
Wire Feed $(\mathrm{mm} / \mathrm{min})$ & $\mathrm{X}_{4}$ & 60 & 80 & 100 \\
\hline
\end{tabular}

Table 2. Experimental results.

\begin{tabular}{|c|c|c|c|c|c|c|}
\hline \multirow{2}{*}{ Exp. No. } & \multicolumn{4}{|c|}{ Coded control factors } & \multirow{2}{*}{$\operatorname{Kerf}(\mathrm{mm})$} & \multirow{2}{*}{$\begin{array}{c}\text { MRR } \\
\left(\mathrm{mm}^{3} / \mathrm{min}\right)\end{array}$} \\
\hline & $\mathrm{X}_{1}$ & $\overline{X_{2}}$ & $\overline{X_{3}}$ & $\overline{X_{4}}$ & & \\
\hline 1 & -1 & -1 & -1 & -1 & 0.214 & 7.381 \\
\hline 2 & -1 & 0 & 0 & 0 & 0.209 & 7.146 \\
\hline 3 & -1 & 1 & 1 & 1 & 0.204 & 7.460 \\
\hline 4 & 0 & -1 & 0 & 1 & 0.216 & 8.929 \\
\hline 5 & 0 & 0 & 1 & -1 & 0.212 & 9.347 \\
\hline 6 & 0 & 1 & -1 & 0 & 0.210 & 4.849 \\
\hline 7 & 1 & -1 & 1 & 0 & 0.215 & 9.415 \\
\hline 8 & 1 & 0 & -1 & 1 & 0.213 & 3.960 \\
\hline 9 & 1 & 1 & 0 & -1 & 0.207 & 4.655 \\
\hline
\end{tabular}

\section{DEVELOPMENT OF EMPIRICAL MODELS}

The mathematical relations were generated with the help of Response Surface Methodology (RSM). The validity of the model has been confirmed by analysis of variance (ANOVA) a tool of Taguchi's method to get interactions between the parameters along with the influence of parameters on the response. First order model has low predictability so higher order model is utilized to cross-check with higher predictability. In Table 3 and Table 4 ANOVA for MRR and kerf are represented. It is observed from the tables that when the value of predictability $(\mathrm{p})$ is less than 0.05 , the significance of the developed model reaches more than $95 \%$ according to statistics [8]. Now the value of multiple regression coefficients $\left(\mathrm{R}^{2}\right)$ has been observed for both MRR and kerf which found to be 0.9546 and 0.9502 respectively suggesting the adequacy of the model up to $95.46 \%$ and $95.02 \%$ for the second order models. The RSM has been utilized for the model development which is given by Wilson et al. and is most effective for development and analysis of quadratic effects between the variables and can be generalized as Eq. (2). 


$$
Y=y-\varepsilon=b_{0}+\sum_{i=1}^{n} b_{i} x_{i}+\sum_{i=1}^{n} b_{i i} x_{i^{2}}+\sum_{i<j} b_{i j} x_{i} x_{j}
$$

In the above equation, the second, third, and fourth term represent linear, second-order, and the interactive effects of the input variables, respectively. The model for MRR and kerf were developed based on Eq. (2) using the different linear and interactive effects and are represented in Eq. (3) \& Eq. (4).

$$
\begin{aligned}
& \text { MRR }=7.016-1.026 X_{1}-1.499 X_{2}+1.850 X_{3}-0.03 X_{4}+0.36 X_{1} X_{2} \\
& -0.08 X_{1} X_{3}-0.73 X_{2} X_{3} \\
& \text { Kerf }=0.211111+0.00033 X_{1}-0.00500 X_{2}-0.00100 X_{3}-0.00100 X_{4} \\
& -0.00000 X_{1} X_{2}-0.00200 X_{1} X_{3}-0.00200 X_{2} X_{3}
\end{aligned}
$$

Table 3. ANOVA for material removal rate.

\begin{tabular}{ccccccc}
\hline Source & $\begin{array}{c}\text { Sum of } \\
\text { squares }\end{array}$ & $\begin{array}{c}\text { Degrees } \\
\text { of } \\
\text { freedom }\end{array}$ & $\begin{array}{c}\text { Mean } \\
\text { square }\end{array}$ & F value & Prob>F & \\
\hline Model & 33.250 & 7 & 4.74644 & 3.00 & 0.418 & Significant \\
$\mathrm{X}_{1}$ & 2.7646 & 1 & 2.76457 & 1.75 & 0.412 & \\
$\mathrm{X}_{2}$ & 3.7737 & 1 & 3.77366 & 2.39 & 0.366 & \\
$\mathrm{X}_{3}$ & 5.7488 & 1 & 5.74881 & 3.63 & 0.308 & \\
$\mathrm{X}_{4}$ & 0.009 & 1 & 0.00095 & 0.00 & 0.984 & \\
$\mathrm{X}_{1} \mathrm{X}_{2}$ & 0.0737 & 1 & 0.07369 & 0.05 & 0.865 & \\
$\mathrm{X}_{1} \mathrm{X}_{3}$ & 0.0035 & 1 & 0.00349 & 0.00 & 0.970 & \\
$\mathrm{X}_{2} \mathrm{X}_{3}$ & 0.6277 & 1 & 0.62772 & 0.40 & 0.642 & \\
Residual & 1.5817 & 1 & 1.58172 & & & \\
Cor total & 34.8068 & 8 & $\mathrm{R}^{2}$ & 0.9546 & & \\
Std. dev. & 1.25766 & & & & & \\
\hline
\end{tabular}

Table 4. ANOVA for the kerf.

\begin{tabular}{ccccccc}
\hline Source & $\begin{array}{c}\text { Sum of } \\
\text { squares }\end{array}$ & $\begin{array}{c}\text { Degrees } \\
\text { of } \\
\text { freedom }\end{array}$ & $\begin{array}{c}\text { Mean } \\
\text { square }\end{array}$ & F value & Prob>F & \\
\hline Model & 0.000119 & 7 & 0.000017 & 2.72 & 0.436 & Significant \\
$\mathrm{X}_{1}$ & 0.000000 & 1 & 0.000000 & 0.05 & 0.864 & \\
$\mathrm{X}_{2}$ & 0.000042 & 1 & 0.000042 & 6.75 & 0.234 & \\
$\mathrm{X}_{3}$ & 0.000002 & 1 & 0.000002 & 0.27 & 0.695 & \\
$\mathrm{X}_{4}$ & 0.000001 & 1 & 0.000001 & 0.14 & 0.774 & \\
$\mathrm{X}_{1} \mathrm{X}_{2}$ & 0.000000 & 1 & 0.000000 & 0.00 & 1.000 & \\
$\mathrm{X}_{1} \mathrm{X}_{3}$ & 0.000002 & 1 & 0.000002 & 0.37 & 0.650 & \\
$\mathrm{X}_{2} \mathrm{X}_{3}$ & 0.000005 & 1 & 0.000005 & 0.75 & 0.546 & \\
Residual & 0.000006 & 1 & 0.000006 & & & \\
Cor total & 0.000125 & 8 & $\mathrm{R}^{2}$ & 0.9502 & & \\
Std. dev. & 0.0024944 & & & & & \\
\hline
\end{tabular}




\section{Calculation of Percentage Absolute Error}

Percentage absolute error has been calculated by comparing each set of respective combination of predicted value and experimental value which can be represented in general form as below [9].

$$
\% \text { Absolute error }=\frac{y_{j . \exp t}-y_{j . p r e d}}{y_{j . \exp t}}
$$

Where $y_{j . e x p t}$ represents experimental values and $y_{j . p r e d}$ represents the predicted value of response for jth trial obtained from RSM models. The values obtained for percentage error using RSM for kerf and MRR are shown in Tables 5 and Table 6. The maximum value for the percentage error is found to be $0.48 \%$ and $9.32 \%$ for kerf and MRR respectively. Thus it shows small deviation in the theoretical value obtained from the model and experimental values thus concluding the acceptance of the model thus generated using RSM and it is considered to be accurate.

Table 5. Percentage absolute error of RSM predictions with experimental results for kerf.

\begin{tabular}{lccc}
\hline Exp. No & $\begin{array}{c}\text { Experimental values } \\
(\mathrm{mm})\end{array}$ & $\begin{array}{c}\text { RSM predicted values } \\
(\mathrm{mm})\end{array}$ & \% absolute error \\
\hline 1 & 0.214 & 0.214 & 0.00 \\
2 & 0.209 & 0.211 & -0.96 \\
3 & 0.204 & 0.204 & 0.00 \\
4 & 0.216 & 0.215 & 0.46 \\
5 & 0.212 & 0.211 & 0.47 \\
6 & 0.210 & 0.209 & 0.48 \\
7 & 0.215 & 0.215 & 0.00 \\
8 & 0.213 & 0.213 & 0.00 \\
9 & 0.207 & 0.207 & 0.00 \\
\hline
\end{tabular}

Table 6. Percentage absolute error of RSM predictions with experimental results for MRR.

\begin{tabular}{lccc}
\hline Exp. No & $\begin{array}{c}\text { Experimental values } \\
\left(\mathrm{mm}^{3} / \mathrm{min}\right)\end{array}$ & $\begin{array}{c}\text { RSM predicted values } \\
\left(\mathrm{mm}^{3} / \mathrm{min}\right)\end{array}$ & $\%$ absolute error \\
\hline 1 & 7.381 & 7.271 & 1.49 \\
2 & 7.146 & 8.042 & -12.54 \\
3 & 7.460 & 7.353 & 1.44 \\
4 & 8.929 & 8.485 & 4.98 \\
5 & 9.347 & 8.896 & 4.83 \\
6 & 4.849 & 4.397 & 9.32 \\
7 & 9.415 & 9.629 & -2.27 \\
8 & 3.960 & 4.190 & -5.82 \\
9 & 4.655 & 4.881 & -4.85 \\
\hline
\end{tabular}

Figure 6 and Figure 7 shows the comparison between the predicted values and experimental values obtained after machining for the responses kerf and MRR using RSM. From the observation, it is clear that there is a very little deviation between the experimental and predicted values obtained from the RSM model which validates the model. 


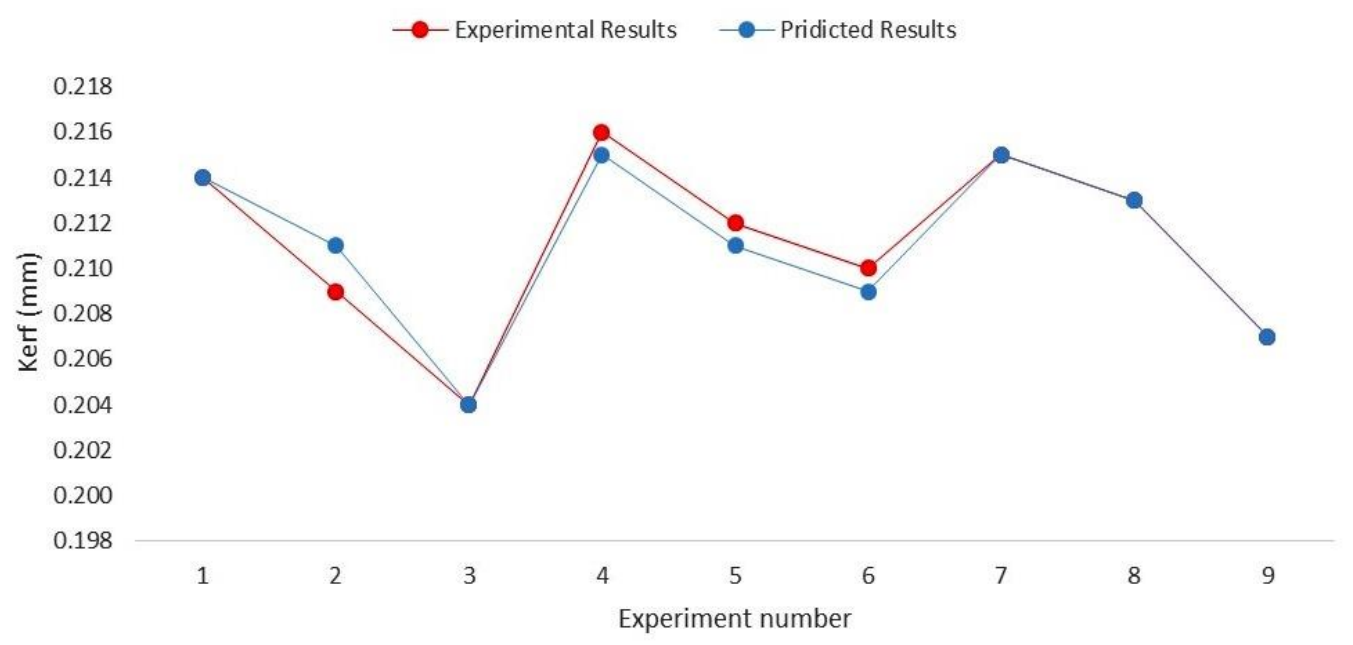

Figure 6. Comparison of RSM predicted values of kerf with experimental values.

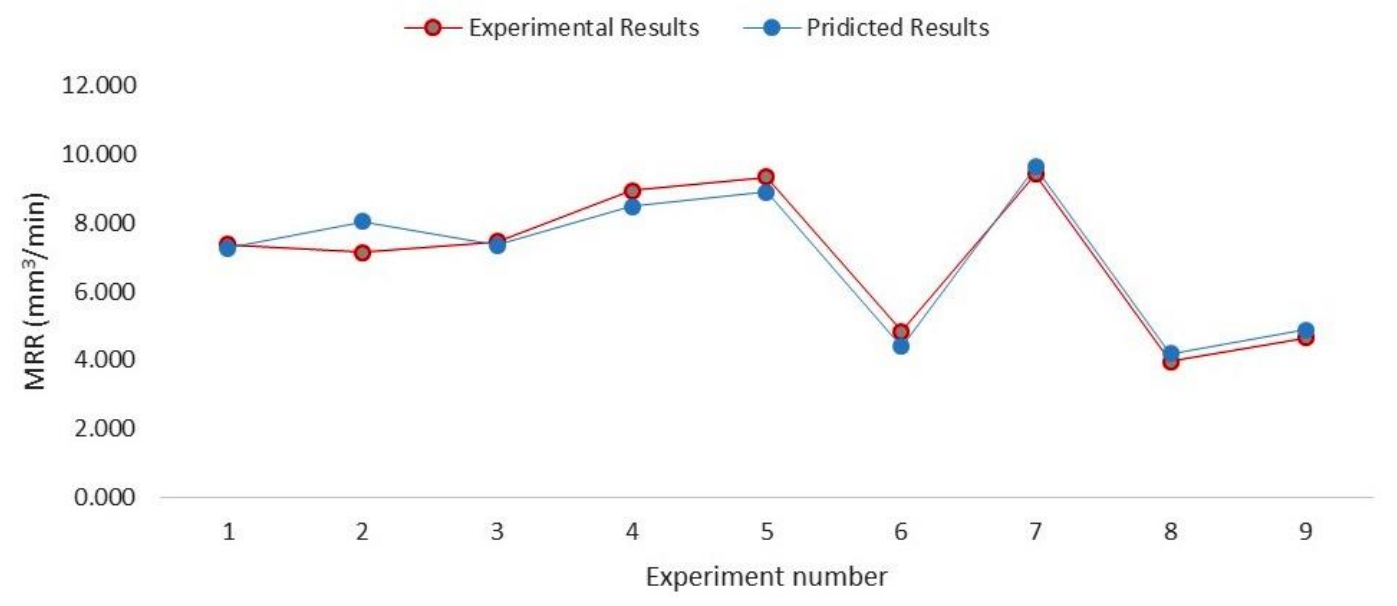

Figure 7. Comparison of RSM predicted values of MRR with experimental values.

\section{RESULTS AND DISCUSSION}

The grey relational analysis is the multi-objective optimization method carried out to find the optimal set of process variables. It consists the following steps [10].

\section{S/N Ratio and normalization of the measured responses}

As the nature of performance measures such as material removal rate and kerf is essential to be maximized and minimized, the larger the better and the lower the better criterion is chosen. The $\mathrm{S} / \mathrm{N}$ ratio for each output response can be calculated by using Eq. (6) and Eq. (7).

(i) Larger-the-better is the criterion:

$$
\frac{S}{N} \text { ratio }=-10 \log _{10}\left(\frac{1}{n} \sum_{i=1}^{n} \frac{1}{y_{i}^{2}}\right)
$$


(ii) Lower-the-better is the criterion:

$$
\frac{S}{N} \text { ratio }=-10 \log _{10}\left(\frac{1}{n} \sum_{i=1}^{n} y_{i}^{2}\right)
$$

Where $n$ the total numbers of runs, $y_{i}$ is the ith value of the measured response.

It is essential to normalize the performance measures before evaluating them as per the grey relational theory [11]. Normalization for the experimental results of each response is carried out and also weighed between 0 and 1 . The performance measures are normalized by using the Eq. (8) for larger the better attributes or criterion and Eq. (9) used for lower the better attributes or criterion.

$$
\begin{aligned}
& Z_{i j}=\frac{y_{i j}-\operatorname{Min}\left\{y_{i j}, i=1,2, \ldots . ., n\right\}}{\operatorname{Max}\left\{y_{i j}, i=1,2, \ldots ., n\right\}-\operatorname{Min}\left\{y_{i j}, i=1,2, \ldots . ., n\right\}} \\
& Z_{i j}=\frac{\operatorname{Max}\left\{y_{i j}, i=1,2, \ldots ., n\right\}-y_{i j}}{\operatorname{Max}\left\{y_{i j}, i=1,2, \ldots ., n\right\}-\operatorname{Min}\left\{y_{i j}, i=1,2, \ldots . ., n\right\}}
\end{aligned}
$$

Where min $y_{i j}$ and max $y_{i j}$ are the minimum and maximum values of the $\mathrm{j}^{\text {th }}$ performance characteristic for the alternative $\mathrm{i}^{\text {th }}$ experiment, and $\mathrm{y}_{\mathrm{ij}}$ is the $\mathrm{j}^{\text {th }}$ performance characteristic in the $i^{\text {th }}$ experiment. The calculated Signal to noise ratio of the separate responses and its normalized values are represented in Table 7.

Table 7. S/N Ratio and normalization of experimental data.

\begin{tabular}{ccccc}
\hline \multirow{2}{*}{ Exp. No } & \multicolumn{2}{c}{ S/N ratio } & \multicolumn{2}{c}{ Normalized values } \\
\cline { 2 - 5 } & MRR & Kerf & MRR & Kerf \\
\hline 1 & 17.362 & 13.392 & 0.627 & 0.167 \\
2 & 17.081 & 13.597 & 0.584 & 0.583 \\
3 & 17.455 & 13.807 & 0.642 & 1.000 \\
4 & 19.016 & 13.311 & 0.911 & 0.000 \\
5 & 19.413 & 13.473 & 0.988 & 0.333 \\
6 & 13.713 & 13.556 & 0.163 & 0.500 \\
7 & 19.476 & 13.351 & 1.000 & 0.083 \\
8 & 11.954 & 13.432 & 0.000 & 0.250 \\
9 & 13.358 & 13.681 & 0.128 & 0.750 \\
\hline
\end{tabular}

\section{Grey relational coefficient and grey relational grade}

After the data processing, the grey relational coefficients for the separate output responses can be calculated from the normalized experimental data values by using formulas represented in Eq. (10).

$$
\left(y_{0}(k), y_{i}(k)\right)=\frac{\Delta \min +\xi \Delta \max }{\Delta_{0 j}+\xi \Delta \max }
$$


Where $\mathrm{j}=1,2, \ldots, \mathrm{n} ; \mathrm{k}=1,2, \ldots, \mathrm{m}, \mathrm{n}$ is the number of experimental data items and $\mathrm{m}$ is the number of responses, $\Delta_{0 \mathrm{j}}=\left\|\mathrm{y}_{0}(\mathrm{k})-\mathrm{y}_{\mathrm{j}}(\mathrm{k})\right\|$ The absolute value of the difference between $\mathrm{y}_{0}(\mathrm{k})$ and $\mathrm{y}_{\mathrm{j}}(\mathrm{k}), \Delta \min =\min \min \left\|\mathrm{y}_{0}(\mathrm{k})-\mathrm{y}_{\mathrm{i}}(\mathrm{k})\right\|$ is the smallest value of $\mathrm{y}_{\mathrm{j}}(\mathrm{k})$, $\Delta \max =\max \max \left\|\mathrm{y}_{0}(\mathrm{k})-\mathrm{y}_{\mathrm{j}}(\mathrm{k})\right\|$ is the largest value of $\mathrm{y}_{\mathrm{j}}(\mathrm{k}), \xi$ is the coefficient constant, which is defined in the range $0 \leq \xi \leq 1$.

The grey relational grade can be calculated from the grey relational coefficient of measured responses for the combined multi-objectives optimization. The grey relational grade is then after ranked in order. The assessment of the output responses is based on grey relational grade and it is determined by using Eq. (11). The calculation of grey relational coefficients of individual responses and grey relational grade values is presented in Table 8 .

$$
\delta_{j}=\frac{1}{k} \sum_{i=1}^{m} y_{i j}
$$

where $\mathrm{k}$ is the no. of performance characteristics and $\delta_{\mathrm{j}}$ is the grey relational grade for the $\mathrm{j}^{\text {th }}$ experimentation.

Table 8. Grey relational coefficients of individual responses, grey relational grade, and rank.

\begin{tabular}{ccccc}
\hline Exp. No & GRC $($ MRR $)$ & GRC (kerf) & GRG & Rank \\
\hline 1 & 0.573 & 0.375 & 0.533 & 6 \\
2 & 0.546 & 0.545 & 0.546 & 5 \\
3 & 0.583 & 1.000 & 0.666 & 4 \\
4 & 0.849 & 0.333 & 0.746 & 3 \\
5 & 0.976 & 0.429 & 0.866 & 2 \\
6 & 0.374 & 0.500 & 0.399 & 8 \\
7 & 1.000 & 0.353 & 0.871 & 1 \\
8 & 0.333 & 0.400 & 0.347 & 9 \\
9 & 0.364 & 0.667 & 0.425 & 7 \\
\hline
\end{tabular}

After calculating the grey relational grade it is essential to find the influence of each variable at different levels based on grey relational grade. Grade values for each level as well as an average of the grade values are shown in Table 9. It follows the general trend as higher the value of grey relational grade value, better or improved output response. The optimum conditions as identified from the response table (pulse on time $=10 \mu \mathrm{s}$, pulse off time $=7 \mu \mathrm{s}$, peak current $\left.=3 \mathrm{Amp}, \mathrm{WF}=60 \mathrm{~mm} \cdot \mathrm{min}^{-1}\right)$.

Table 9. Average of grey relational grade values for each level.

\begin{tabular}{ccccc}
\hline Parameters & \multicolumn{3}{c}{ Levels } & \multirow{2}{*}{ Maximum- Minimum } \\
\cline { 2 - 4 } & 1 & 2 & 3 & \\
\hline $\mathrm{T}_{\text {on }}$ & 0.582 & 0.670 & 0.547 & 0.123 \\
$\mathrm{~T}_{\text {off }}$ & 0.717 & 0.586 & 0.497 & 0.220 \\
$\mathrm{IP}$ & 0.426 & 0.572 & 0.801 & 0.375 \\
$\mathrm{WF}$ & 0.608 & 0.605 & 0.586 & 0.022 \\
\hline \multicolumn{2}{l}{ Mean value of grey relational grade $=0.600$} & \\
\hline
\end{tabular}




\section{CONFIRMATION TEST}

To verify the optimal combination of the parameters and its levels, a confirmation test is required which can be confirmed by conducting experiments with the same set of parameters and after experimental data to be used to confirm the theoretical values to find the enhancement in the grey relational grade. In Table 10, improvement in performance for the WEDM process is revealed. The improvement is found to be 0.334 .

Table 10 Confirmation test.

\begin{tabular}{|c|c|c|c|}
\hline & Initial Parameter & Predicted & Experimental \\
\hline Levels & $\begin{array}{c}\mathrm{T}_{\mathrm{on}}=8, \mathrm{~T}_{\text {off }}=7, \\
\mathrm{IP}=1, \mathrm{WF}=60\end{array}$ & $\begin{array}{l}T_{\text {on }}=10, T_{\text {off }}=7, \\
I P=3, W F=60\end{array}$ & $\begin{array}{l}T_{\text {on }}=10, T_{\text {off }}=7, \\
I P=3, W F=60\end{array}$ \\
\hline $\begin{array}{l}\text { Grey relational } \\
\text { grade }\end{array}$ & 0.533 & 0.996 & 0.867 \\
\hline $\begin{array}{l}\text { Improvement } \\
\text { in grade }\end{array}$ & - & - & 0.334 \\
\hline
\end{tabular}

\section{CONCLUSION}

- With the demand of precision machining for applications of materials like metal matrix composites, there is need of an optimal set of process parameters for the improvement in responses, like MRR and kerf for the materials like LM6, which is reinforced with $\mathrm{SiC}_{\mathrm{p}}$ particles to form MMC.

- Experiments were designed based on Taguchi's design of experiments with the L9 orthogonal array to minimize the number of experiments on Minitab 17. After that empirical model was developed by using RSM and its adequacy has been confirmed by both logically as well as experimentally by conducting confirmatory experiments.

- The grey relational analysis has been adopted to analyze the multi-objective function thus developed and improved in grey relational grade is found to be 0.334 which signifies the improvement in both responses simultaneously with the values of input parameters as variables at pulse on time $10 \mu \mathrm{s}$, pulse off time $7 \mu \mathrm{s}$, peak current 3 Amp, and wire feed $60 \mathrm{~mm} \cdot \mathrm{min}^{-1}$.

- Kerf and material removal rate are considered as the main response to form model using response surface methodology. The values obtained from RSM model are compared with experimental values, it is found that the predicted values given by RSM show closeness with the experimental values. The percentage error between predicted values and experimental results is found to be within $10 \%$, which concludes the theoretical validity of the developed mathematical models. This indicates that the model thus developed agrees to that of the experimental values and is adequate.

- The new response parameter can be the thickness of kerf layer developed due to spark erosion of the metal during the machining as it's the weaker part after the machining due to heat affected zone as well as new metal deposit forming a layer during the machining using spark erosion. It can be studied in future with the development of the technology. 


\section{REFERENCES}

[1] Tosun N, Cogun C, Tosun G. A study on kerf and material removal rate in wire electrical discharge machining based on Taguchi method. Journal of Materials Processing Technology. 2004; 152: 316-322.

[2] Wang ZQ, Spedding TA. Parametric optimization and surface characterization of wire electrical discharge machining process. Precision Engineering. 1997; 20: $5-15$.

[3] Su HC, Liao YS, Huang JT. A study on the machining-parameters optimization of wire electrical discharge machining. Journal of Materials processing Technology. 1997; 71: 487-493.

[4] Lee TC, Lok YK. Processing of advanced ceramics using the wire-cut EDM process. Journal of Materials processing Technology. 1997; 63: 839-843.

[5] Hsue WJ, Huang JT, Liao YS. Determination of finish-cutting operation number and machining parameters setting in wire electrical discharge machining. Journal of Materials processing Technology. 1999; 87: 69-81.

[6] Rozenek M, Kozak J, DabroVwki L, LubkoVwki K. Electrical discharge machining characteristics of metal matrix composites. Journal of Materials processing Technology. 2001; 109: 367-370.

[7] Arikatla SP, Mannan KT, Krishnaiah A. Experimental Investigations on Kerf width and Material Removal Rate in Wire Electric Discharge Machining of Titanium Alloy. International Journal of Emerging Research in Management \&Technology. 2015; 4: 105-109.

[8] Rao TB, Krishna AG. Selection of optimal process parameters in WEDM while machining Al7075/SiCp metal matrix composites. International Journal of Advanced Manufacturing Technology. 2014; 73: 299-314.

[9] Karnik SR, Gaitonde VN, Davim JP. A comparative study of the ANN and RSM modeling approaches for predicting burr size in drilling. International Journal of Advanced Manufacturing Technology. 2008; 38: 868-883.

[10] Kumar SS, Uthayakumar M, Kumaran ST, Parameswaran P, Mohandas E, Kempulraj G, Babu BSR, Natarajan SA. Parametric optimization of wire electrical discharge machining on aluminum-based composites through grey relational analysis. Journal of Manufacturing Processes. 2015; 20: 33-39.

[11] Noorul HA, Marimuthu P, Jeyapaul R. Multi-response optimization of machining parameters of drilling $\mathrm{Al} / \mathrm{SiC}$ metal matrix composite using grey relational analysis in the Taguchi method. International Journal of Advanced Manufacturing Technology. 2008; 37: 250-255. 